\title{
Cellular heterogeneity map of diverse immune and stromal phenotypes within breast tumor microenvironment
}

\author{
Yuan Li ${ }^{\text {Corresp., } 1}$, Zuhua Chen ${ }^{2}$, Long Wu ${ }^{1}$, Junjie Ye ${ }^{1}$, Weiping Tao ${ }^{\text {Corresp. } 1}$ \\ 1 Department of Oncology, Renmin Hospital of Wuhan University, Wuhan, China \\ 2 Department of Oncology, Tongji Hospital, Tongji Medical College, Huazhong University of Science and Technology, Wuhan, China \\ Corresponding Authors: Yuan Li, Weiping Tao \\ Email address: liyuanpumc@gmail.com, taowpwp@sina.com
}

Background: Cellular heterogeneity within the tumor microenvironment is essential to tumorigenesis and tumor development. A high-resolution global view of the tumor-infiltrating immune and stromal cells in breast tumors is needed.

Methods: xCell was used to create a cellular heterogeneity map of 64 cell types in 1,092 breast tumor and adjacent normal tissues. xCell digitally dissects tissue cellular heterogeneity based on gene expression. Integrated statistical analyses were then performed.

Results: There were noticeable differences between the cell fractions in tumor tissues and normal tissues. Tumors displayed higher proportions of immune cells, including CD4+ Tem, CD8+ naïve T cells, and CD8+ Tcm compared with normal tissues. Immune inhibitory receptors (PD1, CTLA4, LAG3 and TIM3) were co-expressed on certain subtypes of T cells in breast tumors, and PD1 and CTLA4 were both positively correlated with CD8+ Tcm and CD8+ T cells. 28 cell types were significantly associated with overall survival in univariate analysis. CD4+ Tem, CD8+ Tcm, CD8+ T-cells, CD8+ naive T-cells, and $B$ cells were positive prognostic factors but $\mathrm{CD} 4+$ naive $\mathrm{T}$-cells were negative prognostic factors for breast cancer patients. TDRD6 and TTK are promising T cell and B cell targets for tumor vaccines. Endothelial cells and fibroblasts were significantly less prevalent in tumor tissues; astrocytes and mesangial cells were negatively correlated with the T stage. Mesangial cells and keratinocytes were found to be favorable prognostic factors and myocytes were negative prognostic factors. Five cell types were found to be independent prognostic factors and we used these to create a reliable prognostic model for breast cancer patients. Cellular heterogeneity was discovered among different breast cancer subtypes by Her2, ER, and PR status. Tri-negative patients had the highest fraction of immune cells while luminal type patients had the lowest. The various cells may have diverse or opposing roles in the prognosis of breast cancer patients.

Conclusions: We created a unique cellular map for the diverse heterogeneity of immune and stromal phenotypes within the breast tumor microenvironment. This map may lead to potential therapeutic targets and biomarkers with prognostic utility. 
1 Cellular heterogeneity map of diverse immune and stromal phenotypes within breast tumor microenvironment

51 Department of Oncology, Renmin Hospital of Wuhan University, Wuhan, China

62 Department of Oncology, Tongji Hospital, Tongji Medical College, Huazhong University

7 of Science and Technology, Wuhan, Hubei Province, China.

$9{ }^{*}$ Correspondence to: Yuan Li and Weiping Tao, Department of Oncology, Renmin

10 Hospital of Wuhan University, No.99, Zhangzhidong Road, Wuhan, 430060, China.

11 Tel: +86-27-88041911-82291.

12 Email: liyuanpumc@gmail.com; taowpwp@sina.com 


\section{Abstract}

Background: Cellular heterogeneity within the tumor microenvironment is essential to tumorigenesis and tumor development. A high-resolution global view of the tumorinfiltrating immune and stromal cells in breast tumors is needed.

Methods: xCell was used to create a cellular heterogeneity map of 64 cell types in 1,092 breast tumor and adjacent normal tissues. xCell digitally dissects tissue cellular heterogeneity based on gene expression. Integrated statistical analyses were then performed.

Results: There were noticeable differences between the cell fractions in tumor tissues and normal tissues. Tumors displayed higher proportions of immune cells, including CD4+ Tem, CD8+ naïve T cells, and CD8+ Tcm compared with normal tissues. Immune inhibitory receptors (PD1, CTLA4, LAG3 and TIM3) were co-expressed on certain subtypes of T cells in breast tumors, and PD1 and CTLA4 were both positively correlated with CD8+ Tcm and CD8+ T cells. 28 cell types were significantly associated with overall survival in univariate analysis. CD4+ Tem, CD8+ Tcm, CD8+ T-cells, CD8+ naive T-cells, and $B$ cells were positive prognostic factors but CD4+ naive T-cells were negative prognostic factors for breast cancer patients. TDRD6 and TTK are promising T cell and B cell targets for tumor vaccines. Endothelial cells and fibroblasts were significantly less prevalent in tumor tissues; astrocytes and mesangial cells were negatively correlated with the $T$ stage. Mesangial cells and keratinocytes were found to be favorable prognostic factors and myocytes were negative prognostic factors. Five cell types were found to be 
36 independent prognostic factors and we used these to create a reliable prognostic model

37 for breast cancer patients. Cellular heterogeneity was discovered among different breast

38 cancer subtypes by Her2, ER, and PR status. Tri-negative patients had the highest

39 fraction of immune cells while luminal type patients had the lowest. The various cells may

40 have diverse or opposing roles in the prognosis of breast cancer patients.

41 Conclusions: We created a unique cellular map for the diverse heterogeneity of immune and stromal phenotypes within the breast tumor microenvironment. This map may lead to potential therapeutic targets and biomarkers with prognostic utility. 


\section{Introduction}

Breast cancer is a common cancer in women and drug resistance and distal metastasis remain major causes of mortality despite improvements in the early diagnosis and treatment of the disease (Cassetta \& Pollard, 2017). Tumors have complex microenvironments composed of malignant cells, immune cells, and stromal infiltrate. Growing evidence suggests that this microenvironment plays a fundamental role in the development of malignancy and resistance to therapy (Noy \& Pollard, 2014). Tumorinfiltrating cells can demonstrate either tumor-suppressing or tumor-promoting effects, depending on the cancer type. For instance, regulatory $\mathrm{T}$ cells (Tregs) and tumor associated macrophages (TAMs) are associated with pro-tumor functions (De Palma \& Lewis, 2013; Nishikawa \& Sakaguchi, 2014; Noy \& Pollard, 2014), but CD8+ T cells are associated with improved clinical outcomes and better responses to immunotherapy (Tumeh et al., 2014). Research in cancer immunology has led to the development and approval of checkpoint blockers. These remarkably effective drugs augment $\mathrm{T}$ cell activity by blocking cytotoxic lymphocyte antigen-4 (CTLA4), programmed cell death protein 1 (PD1), and PD1 ligand (PDL1).

A better understanding of the cellular heterogeneity within the tumor microenvironment may reveal predictive biomarkers, improve existing treatments, and help to develop novel therapeutic strategies. Cellular heterogeneity is traditionally determined using flow cytometry and immunohistochemistry, however, these methods are extremely difficult to apply to solid tumors with limited throughput (Gentles et al., 
2015). Bioinformatics advancements have created novel methods that dissect cellular heterogeneity based on gene expression profiles (Abbas et al., 2009; Newman et al., 2015; Rooney et al., 2015; Shen-Orr \& Gaujoux, 2013). For instance, CIBERSORT can estimate the abundances of 22 immune cell types (Newman et al., 2015). However, rare subsets of immune cells and stromal cells recognized to be important in the promotion or inhibition of tumor growth, invasion, and metastasis are ignored by CIBERSORT (Galon et al., 2006; Hanahan \& Coussens, 2012). xCell can define 64 cell types within tissues, including immune and stroma cells (Aran et al., 2017a; Aran et al., 2017b). Recent analysis with $x$ Cell reveals that plasma cells and $\mathrm{CD} 4+\mathrm{Tcm}$ in the tumor microenvironment may play a role in the progression of triple-negative breast cancer (Deng et al., 2019), although only immune cells were investigated. We used xCell to digitally depict the cellular heterogeneity map within the breast tumor microenvironment to reveal potential interactions and to uncover predictive biomarkers or therapeutic targets for breast cancer.

\section{Methods and materials}

\section{Data curation and cohort characteristics}

The RNA-seq data and clinical parameters from 1,092 patients with breast cancer were obtained from The Cancer Genome Atlas (TCGA) data portal (https://portal.gdc.cancer.gov/). Of the 1,092 breast cancer patients included in this study, 112 paired normal tissues were identified and recurrent tumor tissues were excluded. The clinical characteristics of the cohort are listed in Table 1. 276 known Cancer/Testis (CT) 
87 genes were downloaded from CTDatabase (http://www.cta.Incc.br/).

\section{Bioinformatics analysis}

xCell (http://xcell.ucsf.edu/) is a high-resolution gene-signature-based method for cell type enrichment for up to 64 cell types, including immune and stroma cells. We used xCell $\mathrm{R}$ package (Aran et al., 2017a) (Beta version) from GitHub in $\mathrm{R}$ (version 3.3.1) to deconvolute the cellular heterogeneity within the breast tumor microenvironment from RNA sequencing data. We determined the cellular heterogeneity of 1,092 breast tumor tissues and 112 normal tissues using the xCell method. The 64 cell types were divided into four groups, including 34 immune cells, 13 stromal cells, 9 stem cells, and 8 other cells (Table 2). Over half of the 64 cell types were immune cells, providing a full view of the innate and adaptive immune status with detailed cell subtypes, including CD4+ naive cells, CD4+ T-cells, CD4+ Tcm, and CD4+ Tem. Stromal cells, including fibroblasts, osteoblasts, and pericytes were also included. ImmuneScore and StromaScore were generated by the xCell package using the sums of fractions of certain cell types (Aran et al., 2017b). Tests for differences and correlations were performed. We used the tDistributed Stochastic Neighbor Embedding (t-SNE) method with tsne package (version 0.1-3) to perform cluster analysis based on cell fraction types.

\section{Survival analysis}

Univariate and multivariate COX regressions were performed using the survival package (version 3.1-7) to search for survival-associated genes. The best cutoff value for each factor was determined using the Survminer package (version 0.4.6). Significant 
108

109

110 five independent factors including CD8+ T cells, mesangial cells, NKT, keratinocytes, and

111 class-switched memory B cells. We used the survivalROC package (Version 1.0.3) in R,

112 which uses a time-dependent ROC curve estimation with censored data (Heagerty et al.,

1132000 ) to compare the aptitude of the individual prognostic factors. The final prognostic

114 model was used to generate the area under the curve (AUC) of the receiver-operator

115 characteristic (ROC) curve for each parameter. 
129

130

131

132

133

134

135

136

137

138

139

140

141

142

143

144

145

146

147

cells with red to light blue markers whereas normal tissue had larger proportions of stem and stromal cells with blue to red markers (Figure 1A). Unsupervised cluster analysis revealed that breast tumor tissues and the adjacent normal tissues were clustered into different groups. Immune cells were also clustered into several subgroups (Figure 1B), indicating that the cellular heterogeneity in tumor vs. normal tissues was much greater than that in a single sample. Dimensionality reduction and visualization by t-Distributed Stochastic Neighbor Embedding (t-SNE) also suggested clear difference between the tumor and normal tissues (Figure 1C).

We compared the fractions of each cell type between breast tumor and normal tissues, revealing dramatic differences in the number of cell types between the tumor and normal tissues (Figure 1D-W). Immune cells tended to be more diverse compared to stem or stromal cells. For innate immune cells, neutrophils were more prevalent in normal tissues whereas eosinophils were higher in tumor tissues (Figure 1D-E). There was not a significant difference in DC cells between normal and tumor tissues. However, iDC was significantly lower in tumor tissues but $\mathrm{pDC}$ and $\mathrm{aDC}$ were significantly higher (Figure 1F-I). This phenomenon was also seen in macrophages, in which macrophage M1 was higher in tumor tissues while macrophage M2 was lower (Figure 1J-K). CD4+ Tcm was found to be significantly lower in tumor tissues, while CD4+ Tem, CD8+ naïve T cells, and CD8+ Tcm were significantly higher (Figure 1L-O). Plasma cells, pro B cells, Tgd, Th1, Th2 cells, and Tregs were also found to be significantly higher in tumor tissues (Figure 1P-U). Representative stromal cells, such as endothelial cells and fibroblasts, were found 
150 to be significantly lower in tumor tissues (Figure 1V-W). Differential analysis with paired

151 tumor and normal tissues showed similar patterns (Table 2).

152

153

154

155

156

157

\section{Inhibitory receptors were co-expressed on certain subtypes of T cells}

Inhibitory receptors, including PD1, CTLA4, LAG3, and TIM3, expressed on T cells often led to T-cell exhaustion allowing tumors to evade the immune response (Huang et al., 2017; Nirschl \& Drake, 2013). The use of specific antibodies to inhibit CTLA4 or PD1 and overcome immune suppression and tumor regression is promising (Brahmer et al., 2012; Callahan et al., 2010).

We investigated the correlations between these inhibitory receptors and CD4+/CD8+ T cells. Heatmaps suggested that the expression patterns of the inhibitory receptors correlated with specific subsets of $\mathrm{T}$ cells with distinctions between tumor tissues and normal tissues (Figures 2A and 2B). Correlation analyses also demonstrated that CD8+ T-cells, CD8+ Tcm, CD8+ naive T-cells, CD4+ memory T cells, and CD4+ naïve T cells were all positively correlated with expressions of these inhibitory receptors in tumor tissues, especially with PD1 and CTLA4 (P<0.05) (Figures 2C and D). CD8+ Tem, CD4+ Tcm, and CD4+ T-cells were not strongly correlated with the expressions of the inhibitory receptors (Figure 2C). Only a few T cells were significantly correlated with these inhibitory receptors in normal tissues; TIM3 expression was negatively correlated with CD4+ Tcm

(Figure 2C and F). We observed a significant correlation among the expression of inhibitory receptors (Figure $\mathbf{2 E}$ and $\mathbf{G}$ ). 


\section{Cancer/testis genes TDRD6 and TTK show promise as breast cancer targets} expressed in germ cells and different cancers. However, they are not typically seen in normal somatic cells (Scanlan et al., 2002). The limited expression of CT genes makes them ideal cancer and immunotherapy biomarkers.

We studied the antitumor immunity response to antigens generated by CT genes by examining 276 known CT genes (obtained from the CTDatabase) for their association with immune components. The significant associations between immune cells and CT genes $(P<0.001)$ are shown in Figure 3A. Most of the adaptive immune cells were significantly correlated with CT genes. T cells, such as CD8+ T cells and aDC, which belonged to adaptive and innate immune responses, were positively correlated with most of the CT genes (Figure 3A-C). Moreover, two CT genes, TDRD6 and TTK, were positively correlated with a number of immune cells, especially the CD4+/CD8+ T cells

(Figure 3D and E), implying strong host immune reactions to these two cancer antigens.

\section{Cellular heterogeneity correlated with clinical pathology of breast cancer} Cellular heterogeneity is an important part of the tumor microenvironment and is necessary for the growth and development of a tumor. We studied whether certain cell types were significantly correlated with certain clinical parameters, including age, sex, T

191 stage, $\mathrm{N}$ stage, M stage, and TNM stage. A number of cell types were significantly 
192 correlated with clinical parameters, especially $T$ stage and $M$ stage (Figure 4A).

193 Astrocytes, mesangial cells, and mast cells were negatively correlated with the T stage

194 and plasma cells were positively correlated with the T stage (Figure 4B-E). CD4+ Tcm,

195 CD4+ Tem, microvascular (mv) endothelial cells, NKT, and MSC were all significantly

196 higher at the M stage in patients with distal metastasis (Figure 4F-J). CLP was

197 significantly higher at the $\mathrm{N}$ stage in patients with lymph node metastasis (Figure 4K).

198 Th1 cells and MSC were both positively correlated with TNM stage (Figure 4L-M). The

19912 male breast cancer patients studied tended to have higher proportion of CLP and NKT

200 compared with the female breast cancer patients (Figure 4N-O).

\section{Prognostic model with survival associated cell types}

of primary tumors consistently predicts favorable outcomes for a number of tumor types, including breast cancer. Therefore, survival analyses were performed to find survivalassociated cell types within the tumor microenvironment (Figure 5A). Immune cells were more strongly associated with overall survival, especially CD4+ and CD8+ T cells (Figure 5A). Most T cells, including CD8+ T cells, CD8+ Tcm, CD8+ naïve T cells, and CD4 Tem, were favorable prognostic factors. However, high CD4+ naïve T cells were associated with worse overall survival (Figure 5A-M). NKT, class switched memory B cells, NK cells,

$211 \mathrm{cDC}$, and pDC were also significantly associated with overall survival (Figure 5A-M). A

212 number of stromal cells, including mesangial cells and keratinocytes, were favorable 
213 prognostic factors but myocytes were adverse prognostic factors (Figure 5A-M).

214 Multivariate COX regression revealed that CD8+ T cells, mesangial cells, keratinocytes,

215 NKT, and class switched memory B cells were independent prognostic factors. We built

216 a prognosis predictor model with five independent prognostic factors. Our model more

217 reliably determined the survival of breast cancer patients with the highest AUC of ROC of

218 0.708, versus when the factors were analyzed separately (Figure 5N, 50).

\section{Subtypes of breast cancer had diverse phenotypes of cellular heterogeneity}

221 Emerging evidence suggests that the breast cancer transcriptome has a wide range

222 of intratumoral heterogeneity, as well as genomic heterogeneity based on ER, PR, and

223 Her2, which are determined by the tumor cells and immune cells in the surrounding

224 microenvironment (Chung et al., 2017). We explored cellular heterogeneity among

225 different subtypes of breast cancer by Her2, ER, and PR status. 1,092 breast cancer

226 patients were classified into five groups according the clinicopathological parameters

227 provided by TCGA, including 30 Her2+_HR- patients, 59 Her2+_HR+ patients, 426

228 Luminal type (Her2-_HR+) patients, 97 triple negative (Tri-negative) patients, and 480

229 unknown patients (Table 1). The relative proportion of different cells varied widely among

230 these five subtypes (Figure 6). Tri-negative patients had the highest fraction of immune

231 cells while luminal type patients had the smallest fraction of immune cells, especially

232 CD4+ and CD8+ T cells (Figure 6A, Supplementary Figure S1). Cluster analyses from

233 ImmuneScore, StromaScore, and heatmap suggested the absence of certain cell types 
234 used to distinguish these five subtypes (Figure 6B). Furthermore, t-SNE cluster analysis

235 suggested a large difference in tumor-infiltrating cells among these five subtypes (Figure

236 6C and D). B cells, T cells, macrophages, Th cells and stromal cells, including

237 keratinocytes, were significantly differentially enriched in these subtypes (Figure 6E-P

238 and Figure S2). Tri-negative breast cancer tissues had the highest fractions of plasma

239 cells, pro B cells, macrophages M1, Th1, and Th2 cells, but M2 cells had the lowest

240 fraction of macrophages (Figure 6E-L). Keratinocytes, sebocytes, and pericytes were

241 found frequently in Tri-negative breast cancer whereas MSC cells were found in low

242 amounts (Figure 6M-P). Survival analysis revealed interesting differences between the

243 five subtypes (Figure 7). Each subtype of breast cancer had a unique pattern of survival-

244 associated tumor-infiltrating cells. Different cell types may have different functions in the

245 prognosis of breast cancer patients. Keratinocytes had a favorable effect on the

246 prognostic factors while neurons were associated with adverse prognosis factors in

247 luminal type patients (Figure 7A). However, in Tri-negative patients, keratinocytes

248 predicted a worse overall survival and neurons predicted a better overall survival (Figure

249 7D). Taken together, the diversity of cellular heterogeneity among the different subtypes

250 of breast cancers suggested that tumor-infiltrating cells within the tumor

251 microenvironment were essential in shaping the intratumor heterogeneity of breast 252 cancer.

\section{Discussion}


We observed distinct tumor-infiltrating cell types within the tumor microenvironment.

256 The abundance and activation status of these cell types is of interest to researchers for

257 their novel bioinformatic techniques. Tumor-infiltrating cells are known to play important

258 roles in the regulation of tumor proliferation, metastasis, and invasion (Galon et al., 2006;

259 Hanahan \& Coussens, 2012). The rapid accumulation of high-throughput data and the

260 evolution of bioinformatics algorithms allows us to digitally dissect the interactions

261 between tumors cells and tumor-infiltrating cells, including immune cells and stromal cells

262 (Aran et al., 2017a; Hackl et al., 2016). The high-throughput approach may help

263 understand the complexity of the tumor microenvironment and lead to innovations in

264 breast cancer treatment and prognosis. xCell analysis reveals that plasma cells and CD4+

265 Tcm in the tumor microenvironment may play a role in the progression of triple-negative

266 breast cancer (Deng et al., 2019), although only immune cells were investigated.

267 We used the digital deconvolution from xCell to determine the cellular heterogeneity

268 within breast tumor and normal tissues. A total of 64 cell types with more than 30 immune

269 cell types were characterized at high resolution. This was the most studied set of cell

270 types, especially for tumor-infiltrating lymphocytes (TILs). We focused on immune cell

271 types, especially the CD4+/CD8+ T cells, and discovered differences between breast

272 tumor tissues and adjacent normal tissues with polarized enrichment of certain cell types.

273 Our results demonstrated that the expression of inhibitory receptors (including PD1,

274 CTLA4, LAG3, and TIM3) were positively correlated and were associated with certain

275 types of T cells in tumor tissues, especially CD8+ Tcm and CD8+ T cells. CD4+ Tem, 
276 CD8+ Tcm, CD8+ T-cells, CD8+ naive T-cells, and B cells were associated with better

277 prognosis whereas CD4+ naive T-cells were negatively associated with prognosis for

278 breast cancer patients. Innate and adaptive immune cells had active immune responses

279 to tumor antigens, including T cells, B cells and DC. TDRD6 and TTK are promising 280 targets for cancer vaccines that could activate a number of immune cells, especially $\mathrm{T}$

281 cells and B cells. Stromal cells were also widely involved in the development of breast

282 cancer. Endothelial cells and fibroblasts were not observed as frequently in tumor tissues.

283 Astrocytes and mesangial cells were negatively correlated with T stage. Mesangial cells

284 and keratinocytes were favorable prognostic factors and myocytes were adverse

285 prognostic factors. We built a prognosis predictor with survival-associated cell types to

286 determine the overall survival of breast cancer patients. Cellular heterogeneity was also

287 profiled in different subtypes of breast cancer based on Her2, ER, and PR status. Five

288 subtypes of breast cancer demonstrated various phenotypes and the cell types may have

289 had different or opposing roles in each subtype of breast cancer.

290 Immunotherapies, including immune checkpoint blockers, therapeutic vaccines, and

291 engineered T cells are being intensively investigated (Schumacher \& Schreiber, 2015) to

292 determine how tumor cells interact with immune cells. The tumor-immune cell interaction

293 poses considerable challenges since the development of cancer and immune surveillance

294 by innate and adaptive immune cells with plasticity and memory are evolving ecosystems.

295 The complex interplay between solid tumors and host immunity has been widely studied

296 but is not well understood. Tumor infiltrating lymphocytes (TILs) have been associated 
297 with clinical outcomes in many tumor types (Anagnostou \& Brahmer, 2015; Schoenfeld,

298 2015). For example, CD8+ TILs are prognostically favorable in melanoma, colorectal,

299 ovarian, and non-small cell lung cancer. CD8+ TILs are able to kill tumor cells in specific

300 cancers (Yee et al., 2002). Immunity in breast cancer remains largely unstudied with only

301 a few preliminary evaluations on the prognostic value of CD4+/CD8+ T Iymphocytes. The

302 presence of TILs is potentially predictive and prognostic in specific breast cancer

303 subtypes, especially in patients with human epidermal growth factor receptor 2 positive

304 and triple-negative breast cancer. Large adjuvant studies have shown that higher levels

305 of TILs in primary biopsies are associated with improved overall survival and fewer

306 recurrences, regardless of therapy (Adams et al., 2014; Dieci et al., 2015; Loi et al., 2013).

307 We provided detailed information about the immune cells in breast cancer with

308 numerous novel findings. Inhibitory receptors were expressed on certain types of T cells,

309 preferring CD8+ T cells and CD8+ Tcm. The co-expression of PD1, CTLA4, LAG3, and

310 TIM3 were more commonly observed in tumor tissues compared with normal tissues,

311 which may explain the limited effects of a single immune checkpoint inhibitor and the use

312 of combined strategies. The simultaneous inhibition of PD1 and CTLA4 (Wolchok et al.,

313 2013) or TIM3 (Fourcade et al., 2010) in advanced melanoma patients show promise in

314 clinical trials. CD8+ naive T cells versus CD4+ naive T cells were favorable prognostic

315 factors for the overall survival of breast cancer patients, suggesting that not all $\mathrm{T}$ cells

316 were protective. These results suggest that the upregulated co-expression of multiple

317 immune inhibitory receptors may contribute to immune suppression. More attention 
318 should be paid to subtypes of $\mathrm{T}$ cells when using immune checkpoint blockers since

319 immune cells are highly conditional and may have different or even opposing roles in

320 response to tumor cells.

321 Growing evidence suggests that immune cells and tumor cell-extrinsic factors,

322 including fibroblasts, endothelial cells, adipocytes within the tumor microenvironment

323 have important roles in inhibiting apoptosis, enabling immune evasion, and promoting

324 proliferation, angiogenesis, invasion, and metastasis (Whiteside, 2008). We found that

325 endothelial cells were significantly higher in adjacent normal tissues (Figure $1 \mathrm{~J}$ ) and

326 breast cancer patients with metastasis had a higher fraction of microvascular (mv)

327 endothelial cells (Figure 4C). A high level of $\mathrm{mv}$ endothelial cells was significantly

328 associated with worse overall survival (Figure 5A). Recent studies have shown that

329 endothelial cells may promote triple-negative breast cancer cell metastasis via PAI-1 and

330 CCL5 signaling (Zhang et al., 2018). The presence of endothelial cells significantly

331 enhanced the angiogenic activity of breast cancer cells (Buchanan et al., 2012). These

332 results support our analysis and further study of the clinical relevance of these cell types

333 may provide novel insights into the initiation and progression of breast cancer.

334 We analyzed and described the potential roles of different tumor-infiltrating cells. Our

335 study would benefit from additional analysis and experimental validations to further

336 investigate the roles of the 64 types of cells profiled in this study.

\section{Conclusions}

338 We revealed the landscape of cellular heterogeneity at high resolution and provided 
339

340

342

343

344

345

346

347

348

349

350

351

352

353

354

355

356

357

358

359

360

361

362

363

364

365

366

367

368

369

novel insights into cell interactions within the tumor microenvironment in breast cancer.

Our results may assist in the development of future therapeutic and predictive strategies.

Further study should focus on the subtypes of immune cells and stromal cells identified

in this study.

3

4

5

6

47

\section{Reference:}

Abbas AR, Wolslegel K, Seshasayee D, Modrusan Z, and Clark HF. 2009. Deconvolution of blood microarray data identifies cellular activation patterns in systemic lupus erythematosus. PLoS One 4:e6098. 10.1371/journal.pone.0006098

Adams S, Gray RJ, Demaria S, Goldstein L, Perez EA, Shulman LN, Martino S, Wang M, Jones VE, Saphner TJ, Wolff AC, Wood WC, Davidson NE, Sledge GW, Sparano JA, and Badve SS. 2014. Prognostic value of tumor-infiltrating lymphocytes in triple-negative breast cancers from two phase III randomized adjuvant breast cancer trials: ECOG 2197 and ECOG 1199. Journal of Clinical Oncology 32:2959-2966. 10.1200/JCO.2013.55.0491

Anagnostou VK, and Brahmer JR. 2015. Cancer immunotherapy: a future paradigm shift in the treatment of non-small cell lung cancer. Clin Cancer Res 21:976-984. 10.1158/1078-0432.CCR-14-1187

Aran D, Hu Z, and Butte AJ. 2017a. xCell: Digitally portraying the tissue cellular heterogeneity landscape. bioRxiv. $10.1101 / 114165$

Aran D, Hu Z, and Butte AJ. 2017b. xCell: digitally portraying the tissue cellular heterogeneity landscape. Genome Biology 18:220. 10.1186/s13059-017-1349-1

Brahmer JR, Tykodi SS, Chow LQ, Hwu WJ, Topalian SL, Hwu P, Drake CG, Camacho LH, Kauh J, Odunsi K, Pitot HC, Hamid O, Bhatia S, Martins R, Eaton K, Chen S, Salay TM, Alaparthy S, Grosso JF, Korman AJ, Parker SM, Agrawal S, Goldberg SM, Pardoll DM, Gupta A, and Wigginton JM. 2012. Safety and activity of antiPD-L1 antibody in patients with advanced cancer. $N$ Engl J Med 366:2455-2465. 10.1056/NEJMoa1200694

Buchanan CF, Szot CS, Wilson TD, Akman S, Metheny-Barlow LJ, Robertson JL, Freeman JW, and Rylander MN. 2012. Cross-talk between endothelial and breast cancer cells regulates reciprocal expression of angiogenic factors in vitro. Journal of Cellular Biochemistry 113:1142-1151. 10.1002/jcb.23447

Peer] reviewing PDF | (2019:11:43594:1:1:NEW 18 May 2020) 
Callahan MK, Wolchok JD, and Allison JP. 2010. Anti-CTLA-4 antibody therapy: immune monitoring during clinical development of a novel immunotherapy. Semin Oncol 37:473-484. 10.1053/j.seminoncol.2010.09.001

Cassetta L, and Pollard JW. 2017. Repolarizing macrophages improves breast cancer therapy. Cell Research 27:963964. $10.1038 /$ cr.2017.63

Chung W, Eum HH, Lee HO, Lee KM, Lee HB, Kim KT, Ryu HS, Kim S, Lee JE, Park YH, Kan Z, Han W, and Park WY. 2017. Single-cell RNA-seq enables comprehensive tumour and immune cell profiling in primary breast cancer. Nature Communications 8:15081. 10.1038/ncomms15081

De Palma M, and Lewis CE. 2013. Macrophage regulation of tumor responses to anticancer therapies. Cancer Cell 23:277-286. 10.1016/j.ccr.2013.02.013

Deng L, Lu D, Bai Y, Wang Y, Bu H, and Zheng H. 2019. Immune Profiles of Tumor Microenvironment and Clinical Prognosis among Women with Triple-Negative Breast Cancer. Cancer Epidemiology, Biomarkers and Prevention 28:1977-1985. 10.1158/1055-9965.EPI-19-0469

Dieci MV, Mathieu MC, Guarneri V, Conte P, Delaloge S, Andre F, and Goubar A. 2015. Prognostic and predictive value of tumor-infiltrating lymphocytes in two phase III randomized adjuvant breast cancer trials. Annals of Oncology 26:1698-1704. 10.1093/annonc/mdv239

Fourcade J, Sun Z, Benallaoua M, Guillaume P, Luescher IF, Sander C, Kirkwood JM, Kuchroo V, and Zarour HM. 2010. Upregulation of Tim-3 and PD-1 expression is associated with tumor antigen-specific CD8+ T cell dysfunction in melanoma patients. $J$ Exp Med 207:2175-2186. 10.1084/jem.20100637

Galon J, Costes A, Sanchez-Cabo F, Kirilovsky A, Mlecnik B, Lagorce-Pages C, Tosolini M, Camus M, Berger A, Wind P, Zinzindohoue F, Bruneval P, Cugnenc PH, Trajanoski Z, Fridman WH, and Pages F. 2006. Type, density, and location of immune cells within human colorectal tumors predict clinical outcome. Science 313:1960-1964. 10.1126/science.1129139

Gentles AJ, Newman AM, Liu CL, Bratman SV, Feng W, Kim D, Nair VS, Xu Y, Khuong A, Hoang CD, Diehn M, West RB, Plevritis SK, and Alizadeh AA. 2015. The prognostic landscape of genes and infiltrating immune cells across human cancers. Nat Med 21:938-945. 10.1038/nm.3909

Hackl H, Charoentong P, Finotello F, and Trajanoski Z. 2016. Computational genomics tools for dissecting tumourimmune cell interactions. Nat Rev Genet 17:441-458. 10.1038/nrg.2016.67

Hanahan D, and Coussens LM. 2012. Accessories to the crime: functions of cells recruited to the tumor microenvironment. Cancer Cell 21:309-322. 10.1016/j.ccr.2012.02.022

Heagerty PJ, Lumley T, and Pepe MS. 2000. Time-dependent ROC curves for censored survival data and a diagnostic marker. Biometrics 56:337-344.

Huang RY, Francois A, McGray AR, Miliotto A, and Odunsi K. 2017. Compensatory upregulation of PD-1, LAG-3, and CTLA-4 limits the efficacy of single-agent checkpoint blockade in metastatic ovarian cancer. Oncoimmunology 6:e1249561. 10.1080/2162402X.2016.1249561

Loi S, Sirtaine N, Piette F, Salgado R, Viale G, Van Eenoo F, Rouas G, Francis P, Crown JP, Hitre E, de Azambuja E, Quinaux E, Di Leo A, Michiels S, Piccart MJ, and Sotiriou C. 2013. Prognostic and predictive value of tumor-infiltrating lymphocytes in a phase III randomized adjuvant breast cancer trial in node-positive breast cancer comparing the addition of docetaxel to doxorubicin with doxorubicin-based chemotherapy: BIG 0298. Journal of Clinical Oncology 31:860-867. 10.1200/JCO.2011.41.0902

Newman AM, Liu CL, Green MR, Gentles AJ, Feng W, Xu Y, Hoang CD, Diehn M, and Alizadeh AA. 2015. Robust enumeration of cell subsets from tissue expression profiles. Nat Methods 12:453-457. 10.1038/nmeth.3337 
411

412

413

414

415

416

417

418

419

420

421

422

423

424

425

426

427

428

429

430

431

432

433

434

435

436

437

438

439

440

441

442

443

444

445

446

447
Nirschl CJ, and Drake CG. 2013. Molecular pathways: coexpression of immune checkpoint molecules: signaling pathways and implications for cancer immunotherapy. Clin Cancer Res 19:4917-4924. 10.1158/10780432.CCR-12-1972

Nishikawa H, and Sakaguchi S. 2014. Regulatory T cells in cancer immunotherapy. Curr Opin Immunol 27:1-7. 10.1016/j.coi.2013.12.005

Noy R, and Pollard JW. 2014. Tumor-associated macrophages: from mechanisms to therapy. Immunity 41:49-61. 10.1016/j.immuni.2014.06.010

Rooney MS, Shukla SA, Wu CJ, Getz G, and Hacohen N. 2015. Molecular and genetic properties of tumors associated with local immune cytolytic activity. Cell 160:48-61. 10.1016/j.cell.2014.12.033

Scanlan MJ, Gure AO, Jungbluth AA, Old LJ, and Chen YT. 2002. Cancer/testis antigens: an expanding family of targets for cancer immunotherapy. Immunol Rev 188:22-32.

Schoenfeld JD. 2015. Immunity in head and neck cancer. Cancer Immunol Res 3:12-17. 10.1158/2326-6066.CIR-140205

Schumacher TN, and Schreiber RD. 2015. Neoantigens in cancer immunotherapy. Science 348:69-74. 10.1126/science.aaa4971

Shen-Orr SS, and Gaujoux R. 2013. Computational deconvolution: extracting cell type-specific information from heterogeneous samples. Curr Opin Immunol 25:571-578. 10.1016/j.coi.2013.09.015

Tumeh PC, Harview CL, Yearley JH, Shintaku IP, Taylor EJ, Robert L, Chmielowski B, Spasic M, Henry G, Ciobanu V, West AN, Carmona M, Kivork C, Seja E, Cherry G, Gutierrez AJ, Grogan TR, Mateus C, Tomasic G, Glaspy JA, Emerson RO, Robins H, Pierce RH, Elashoff DA, Robert C, and Ribas A. 2014. PD-1 blockade induces responses by inhibiting adaptive immune resistance. Nature 515:568-571. 10.1038/nature13954

Whiteside TL. 2008. The tumor microenvironment and its role in promoting tumor growth. Oncogene 27:5904-5912. 10.1038/onc.2008.271

Wolchok JD, Kluger H, Callahan MK, Postow MA, Rizvi NA, Lesokhin AM, Segal NH, Ariyan CE, Gordon RA, Reed K, Burke MM, Caldwell A, Kronenberg SA, Agunwamba BU, Zhang X, Lowy I, Inzunza HD, Feely W, Horak CE, Hong Q, Korman AJ, Wigginton JM, Gupta A, and Sznol M. 2013. Nivolumab plus ipilimumab in advanced melanoma. $N$ Engl J Med 369:122-133. 10.1056/NEJMoa1302369

Yee C, Thompson JA, Byrd D, Riddell SR, Roche P, Celis E, and Greenberg PD. 2002. Adoptive T cell therapy using antigen-specific CD8 $+\mathrm{T}$ cell clones for the treatment of patients with metastatic melanoma: in vivo persistence, migration, and antitumor effect of transferred T cells. Proc Natl Acad Sci U S A 99:16168-16173. 10.1073/pnas.242600099

Zhang W, Xu J, Fang H, Tang L, Chen W, Sun Q, Zhang Q, Yang F, Sun Z, Cao L, Wang Y, and Guan X. 2018. Endothelial cells promote triple-negative breast cancer cell metastasis via PAI-1 and CCL5 signaling. FASEB Journal 32:276-288. 10.1096/fj.201700237RR 
448 Figure legends:

449 Figure 1. Differences of cellular heterogeneity between breast tumor tissue and

normal tissues. A. Median fractions of 64 cell types in breast tumor and normal tissues.

45164 cell types were grouped into four groups: immune, stem, stromal, and other cells. B.

452 Heatmap of fractions of 64 cell types in 1,092 breast tumor tissues and 112 adjacent

453 normal tissues. C. Dimensionality reduction and visualization by t-Distributed Stochastic

454 Neighbor Embedding (t-SNE) clustering based on cell fractions. D. to W. Dot plots of 455 fractions of certain cell types in breast tumor and normal tissues. Lines between dots 456 indicated paired tissues from the same breast cancer patient. * $, P<0.05 .{ }^{* *}, P<0.01 .{ }^{* *}$, $457 \quad \mathrm{P}<0.001$.

458

Figure 2. Expression patterns of inhibitory receptors on CD4+/CD8+ T cells. A and

B. Heatmaps of expression of inhibitory receptors including PD1, CTLA4, LAG3 and

TIM3, and fractions of CD4+/CD8+ T cells in tumor tissues (A) and normal tissues (B).

Data were transformed by rank and normalized. C. Clustered correlation matrixes among inhibitory receptors and CD4+/CD8+ T cells in tumor tissues (up-right triangle) and normal tissues (low-left triangle). D. Dot plot of correlations between PD1 expression and 465 fractions of CD8+ Tcm in tumor tissues. E. Dot plot of correlations between PD1 expression and CTLA4 expression in tumor tissues. F. Dot plot of correlations between TIM3 expression and fractions of CD4+ Tcm in normal tissues. G. Dot plot of correlations between PD1 expression and LAG3 in normal tissues. 
Figure 3. Correlations between cancer/testis genes and immune cells. A. Significant

471 correlations between cancer/testis (CT) genes and immune cells. Scaled color dots

472 represented significant correlations between CT genes and immune cells $(P<0.001)$ and

473 red dots represented positive correlations while blue dots represent negative correlations.

474 B. and C. CD8+ naïve T-cells and aDC were positively correlated with most of the CT

475 genes. D. and E. TDRD6 and TTK were positively correlated with a number of immune 476 cells.

Figure 4. Involvement of cellular heterogeneity in clinic-pathology of breast cancer.

A. A number of cell types were significantly correlated with clinical parameters. B. to O.

Examples of significant correlations between different cell types and clinical parameters, $y$-axis represents the fractions of each cell type. ${ }^{*}, \mathrm{P}<0.05 .{ }^{* *}, \mathrm{P}<0.01 .{ }^{* * *}, \mathrm{P}<0.001$.

Figure 5. Survival associated tumor-infiltrating cells in breast cancer. A. Forest plot of hazard ratios of survival associated cell types. B. to M. Kaplan-Meier curves of survival associated cell types. Red lines indicated high fraction while blue lines indicated low

fraction of each cell types, respectively. N. Kaplan-Meier curves of predictor built with five independent prognostic factors $(\mathrm{P}<0.01)$. $\mathrm{O}$. ROC curves of prognostic model and the five independent prognostic factors. 
490

491

492

493

494

495

496

497

498

499

500

501

502

503

504

505

506

507

508

Figure 6. Differences of cellular heterogeneity among different subtypes of breast cancer. A. Median fraction of 64 cell types in five subtypes of breast tumor. B. Cluster analysis by ImmuneScore and StromaScore, which were calculated by summing up the fractions of immune and stromal cells, respectively. C. Dimensionality reduction and visualization by t-Distributed Stochastic Neighbor Embedding (t-SNE) clustering with fractions of all the 64 cell types. D. Heatmap of fractions of 64 cell types in five subtypes of breast cancer. E. to P. Box plots with dots of fractions of certain cell types in five subtypes of breast cancer. ${ }^{*}, \mathrm{P}<0.05 .{ }^{* *}, \mathrm{P}<0.01 .{ }^{* * *}, \mathrm{P}<0.001,{ }^{* * * *}, \mathrm{P}<0.0001$.

Figure 7. Survival associated tumor-infiltrating cells in five subtypes of breast cancer. A. to E. Forest plots of hazard ratios of survival associated cell types in five subtypes of breast cancer.

Supplementary Figure S1. Median fractions of 64 types of cells in five subtypes of breast cancer.

Supplementary Figure S2. Diverse differences of 64 types of cells among the five subtypes of breast cancer. 


\section{Figure 1}

Differences of cellular heterogeneity between breast tumor tissue and normal tissues.

A. Median fractions of 64 cell types in breast tumor and normal tissues. 64 cell types were grouped into four groups: immune, stem, stromal, and other cells. B. Heatmap of fractions of 64 cell types in 1,092 breast tumor tissues and 112 adjacent normal tissues. C.

Dimensionality reduction and visualization by t-Distributed Stochastic Neighbor Embedding (t-SNE) clustering based on cell fractions. D. to W. Dot plots of fractions of certain cell types in breast tumor and normal tissues. Lines between dots indicated paired tissues from the same breast cancer patient. *, $\mathrm{P}<0.05$. **, $\mathrm{P}<0.01$. ***, $\mathrm{P}<0.001$. 

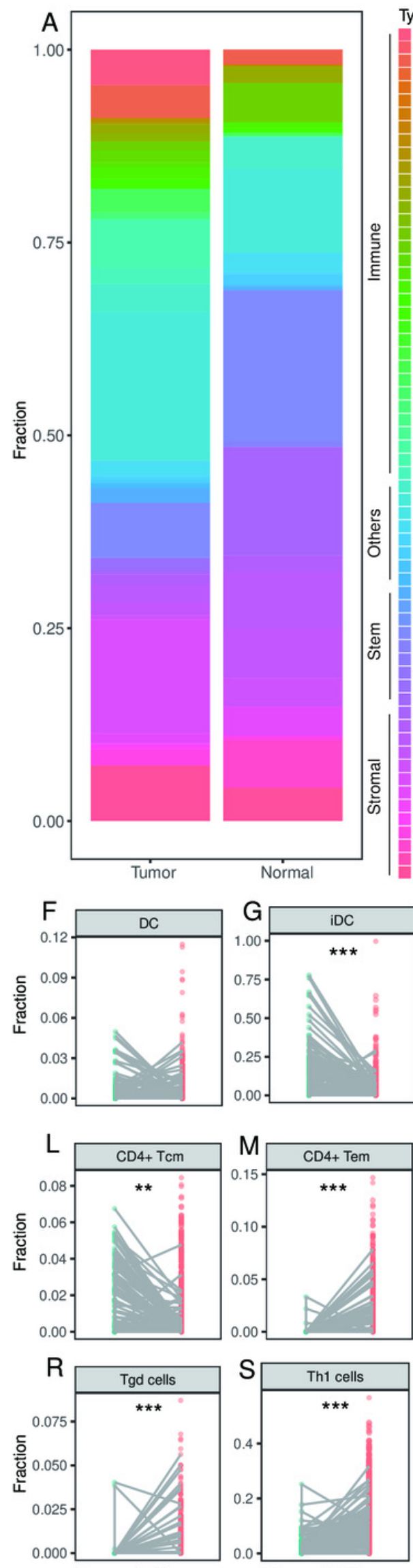

Normal Tumor

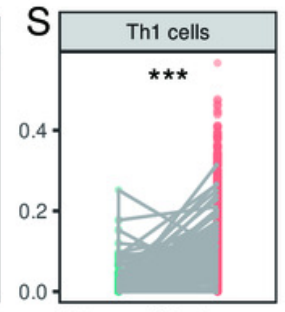

Normal Tumor
Type

aDC
B-cells
Basophils
Cast

CD4+naive T-cells

CD4+T-cells

CD4+Tem

CD4+ memory T-cells

CD8+ naive T-cells

$\mathrm{CD} 8+\mathrm{T}$-cells

$\mathrm{CD} 8+\mathrm{Tcm}$

$\mathrm{CDB}+\mathrm{Tem}$

CDC

DC
Eosinophil
iDC

Macrophages

Macrophages M1

Macrophages M

Memory B-cel

Monocytes

naive $\mathrm{B}$-cells

Neutrophils

NK cells

NKT

Plasma cells

pro B-cells

Tregs

Th2 cells

Astrocytes

Epithelial cells

Hepatocytes
Keratinocytes

Keratinocytes
Melanocytes

Mesangial cells

Neurons

Sebocytes

GMP

HSC

Megakaryocytes

Erythrocytes

Platelets
Adipocytes

Chondrocytes Endothelial cells Fibroblasts
ly Endothelial ce MSC Endothelial cells

mv Endothelial cells Myocytes
Osteoblast Osteoblas: Preadipocytes

Smooth muscle
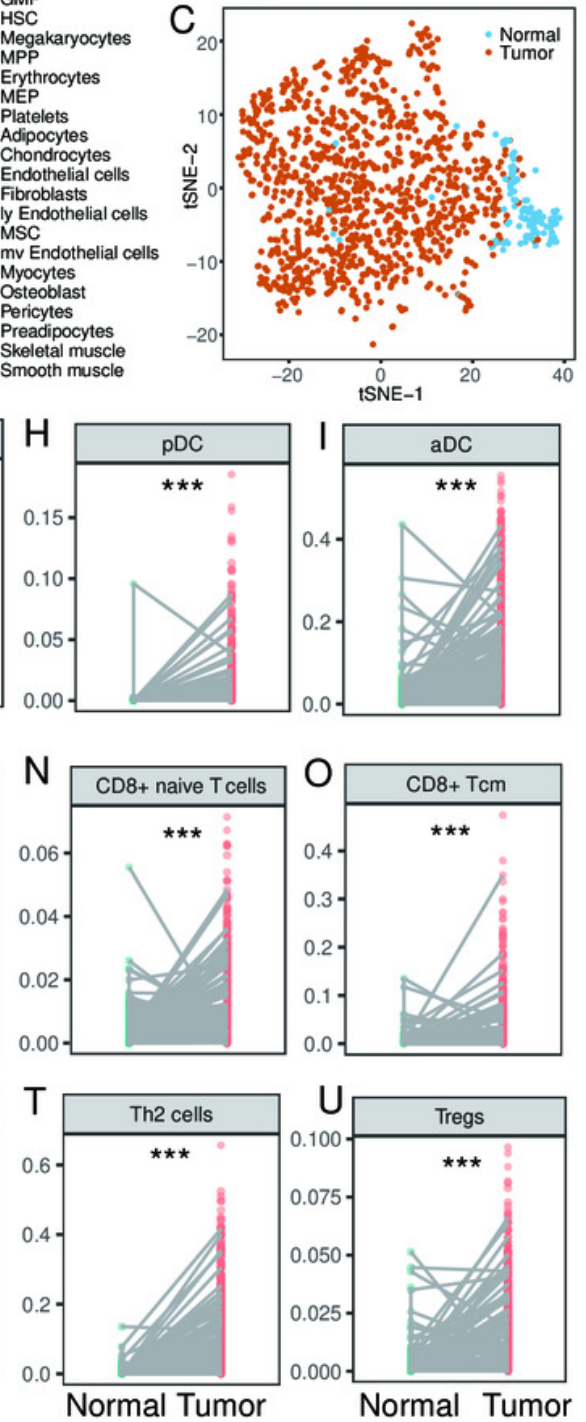

B 융
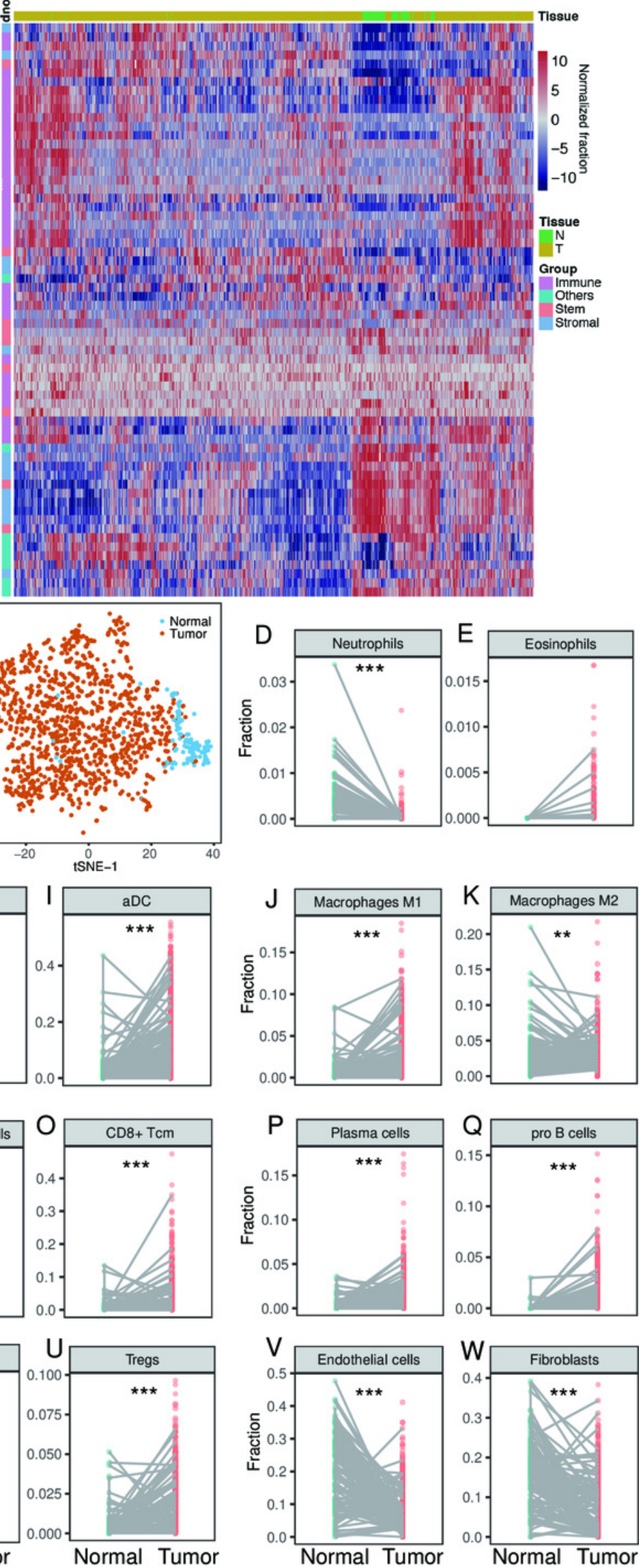


\section{Figure 2}

Expression patterns of inhibitory receptors on CD4+/CD8+ T cells.

A and B. Heatmaps of expression of inhibitory receptors including PD1, CTLA4, LAG3 and TIM3, and fractions of CD4+/CD8 + T cells in tumor tissues (A) and normal tissues (B). Data were transformed by rank and normalized. C. Clustered correlation matrixes among inhibitory receptors and CD4+/CD8 + T cells in tumor tissues (up-right triangle) and normal tissues (low-left triangle). D. Dot plot of correlations between PD1 expression and fractions of CD8+ Tcm in tumor tissues. E. Dot plot of correlations between PD1 expression and CTLA4 expression in tumor tissues. F. Dot plot of correlations between TIM3 expression and fractions of CD4+ Tcm in normal tissues. G. Dot plot of correlations between PD1 expression and LAG3 in normal tissues.

A

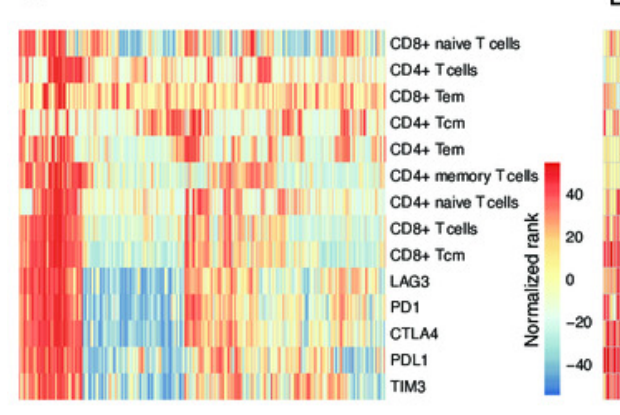

B

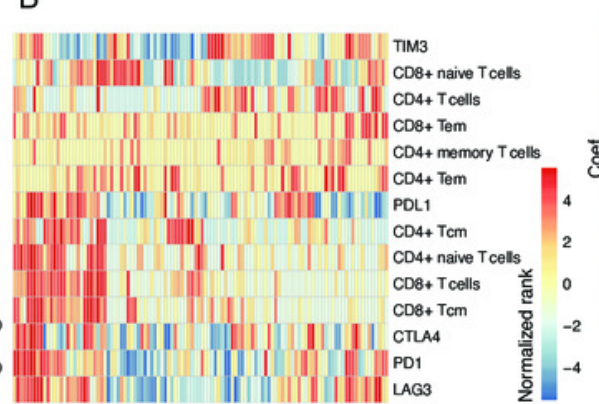

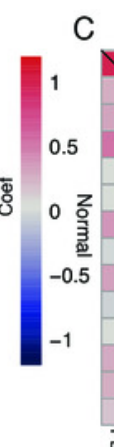

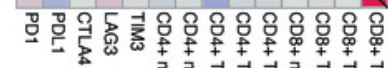

D

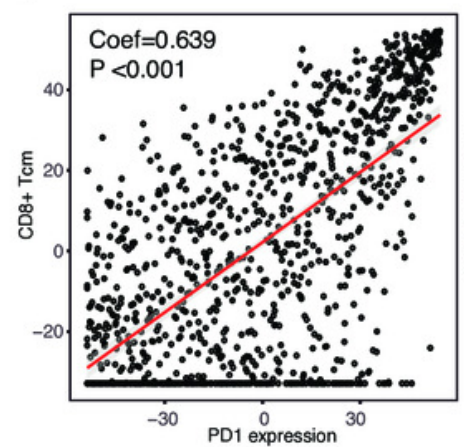

E

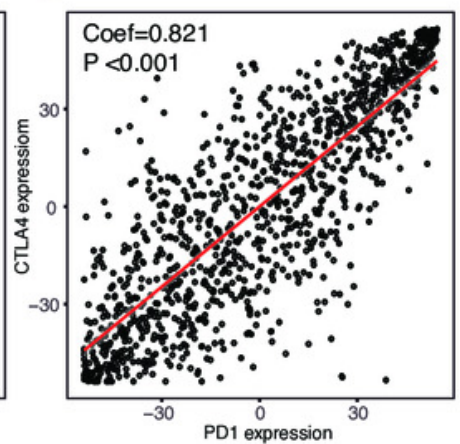

$\mathrm{F}$

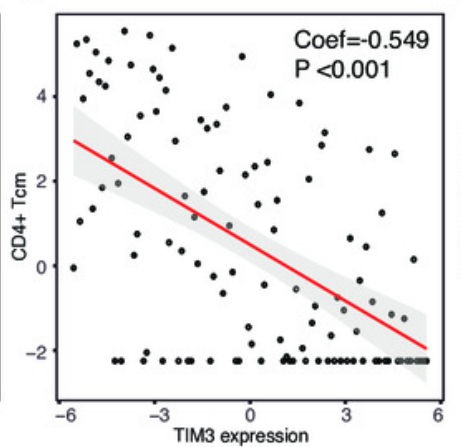

$G$

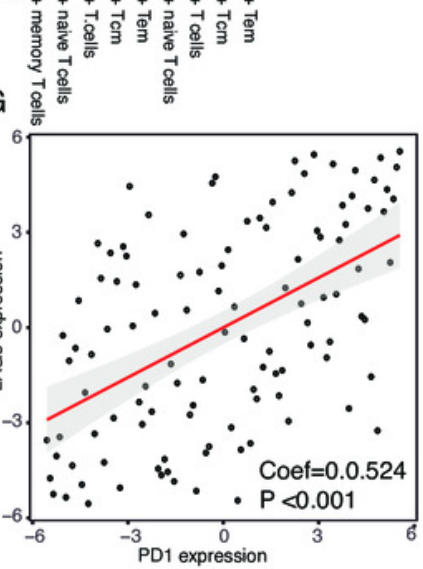




\section{Figure 3}

Correlations between cancer/testis genes and immune cells.

A. Significant correlations between cancer/testis (CT) genes and immune cells. Scaled color dots represented significant correlations between CT genes and immune cells $(P<0.001)$ and red dots represented positive correlations while blue dots represent negative correlations. B. and C. CD8+ naïve T-cells and aDC were positively correlated with most of the CT genes. D. and E. TDRD6 and TTK were positively correlated with a number of immune cells. 

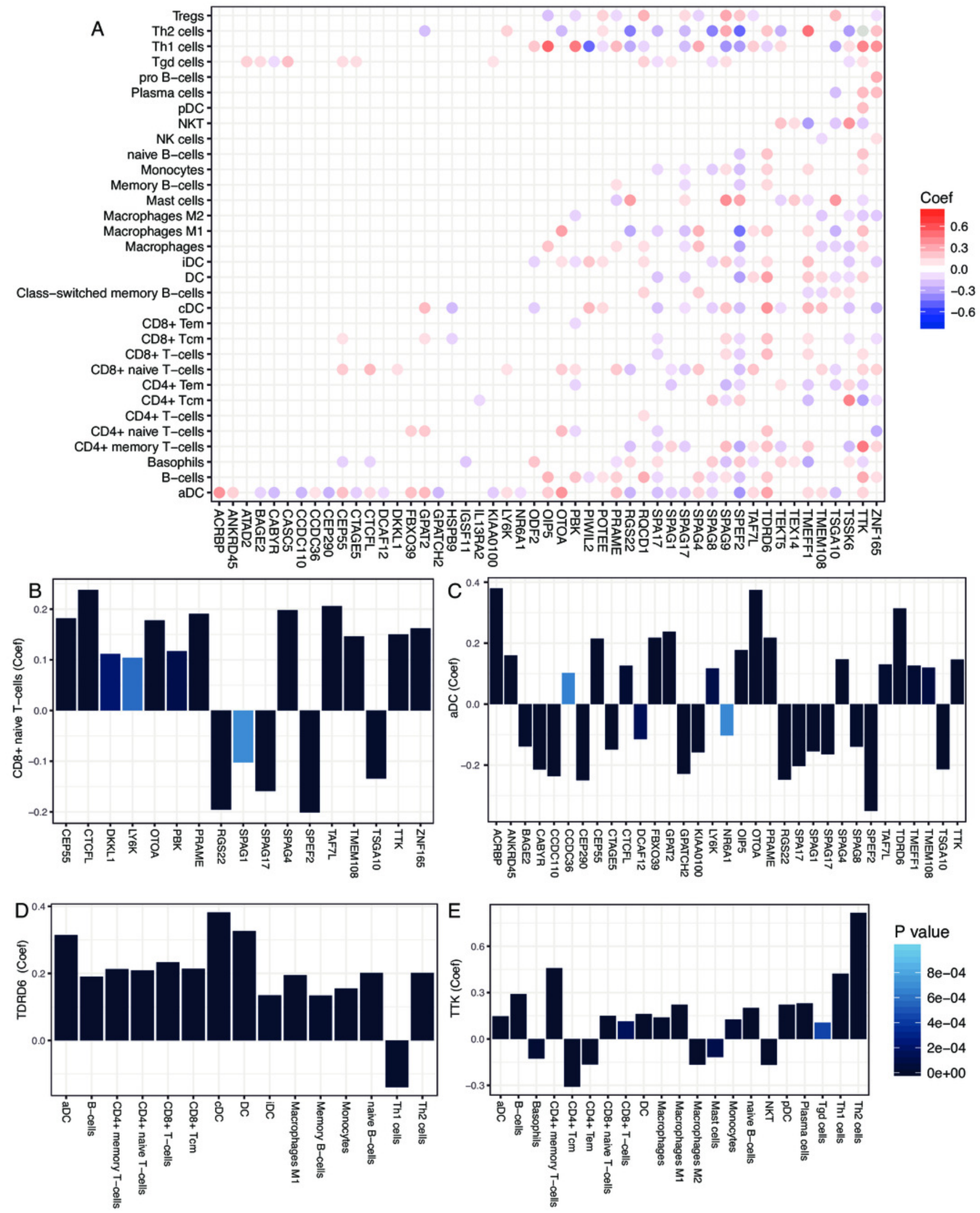

$P$ value

8e-04

6e-04

4e-04

2e-04

0e+00 
Figure 4

Involvement of cellular heterogeneity in clinic-pathology of breast cancer.

A. A number of cell types were significantly correlated with clinical parameters. B. to 0 .

Examples of significant correlations between different cell types and clinical parameters, yaxis represents the fractions of each cell type. $*, \mathrm{P}<0.05$. **, $\mathrm{P}<0.01$. ***, $\mathrm{P}<0.001$. 

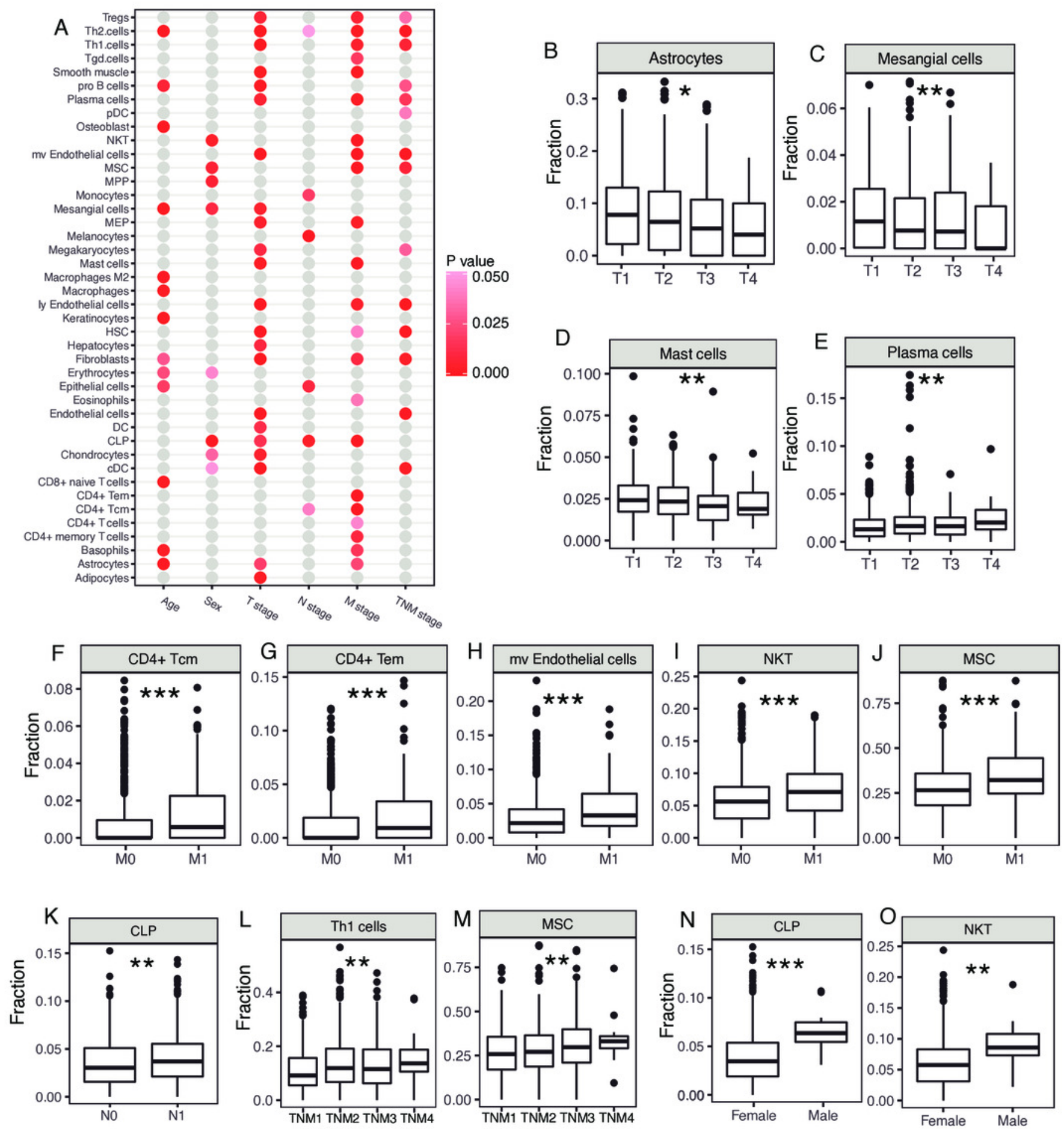


\section{Figure 5}

Survival associated tumor-infiltrating cells in breast cancer.

Forest plot of hazard ratios of survival associated cell types. B. to M. Kaplan-Meier curves of survival associated cell types. Red lines indicated high fraction while blue lines indicated low fraction of each cell types, respectively. N. Kaplan-Meier curves of predictor built with five independent prognostic factors $(\mathrm{P}<0.01)$. $\mathrm{O}$. ROC curves of prognostic model and the five independent prognostic factors. 


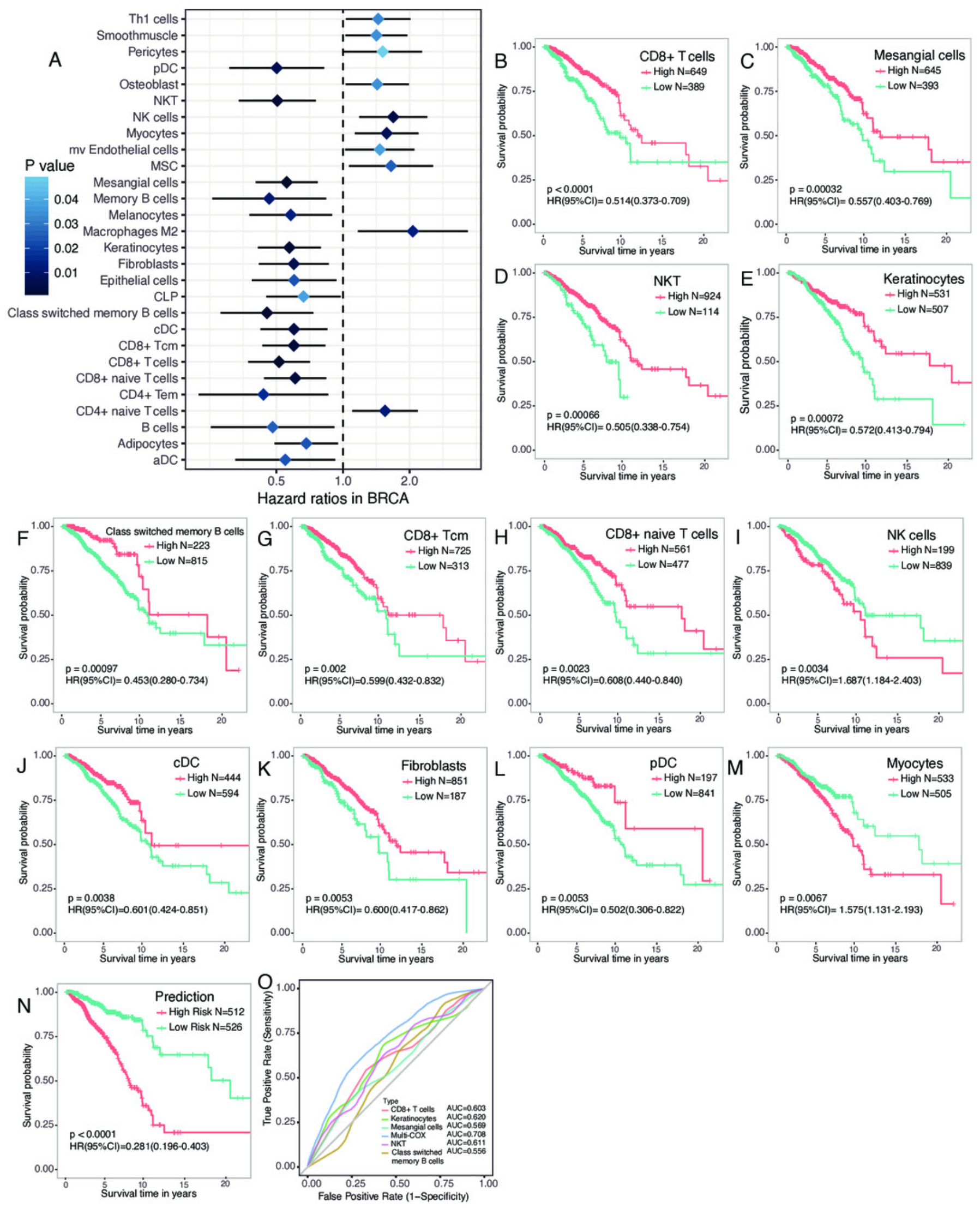




\section{Figure 6}

Differences of cellular heterogeneity among different subtypes of breast cancer.

A. Median fraction of 64 cell types in five subtypes of breast tumor. B. Cluster analysis by ImmuneScore and StromaScore, which were calculated by summing up the fractions of immune and stromal cells, respectively. C. Dimensionality reduction and visualization by tDistributed Stochastic Neighbor Embedding (t-SNE) clustering with fractions of all the 64 cell types. D. Heatmap of fractions of 64 cell types in five subtypes of breast cancer. E. to P. Box plots with dots of fractions of certain cell types in five subtypes of breast cancer. ${ }^{*}, P<0.05$. $* *, \mathrm{P}<0.01$. ***, $\mathrm{P}<0.001, * * * *, \mathrm{P}<0.0001$. 


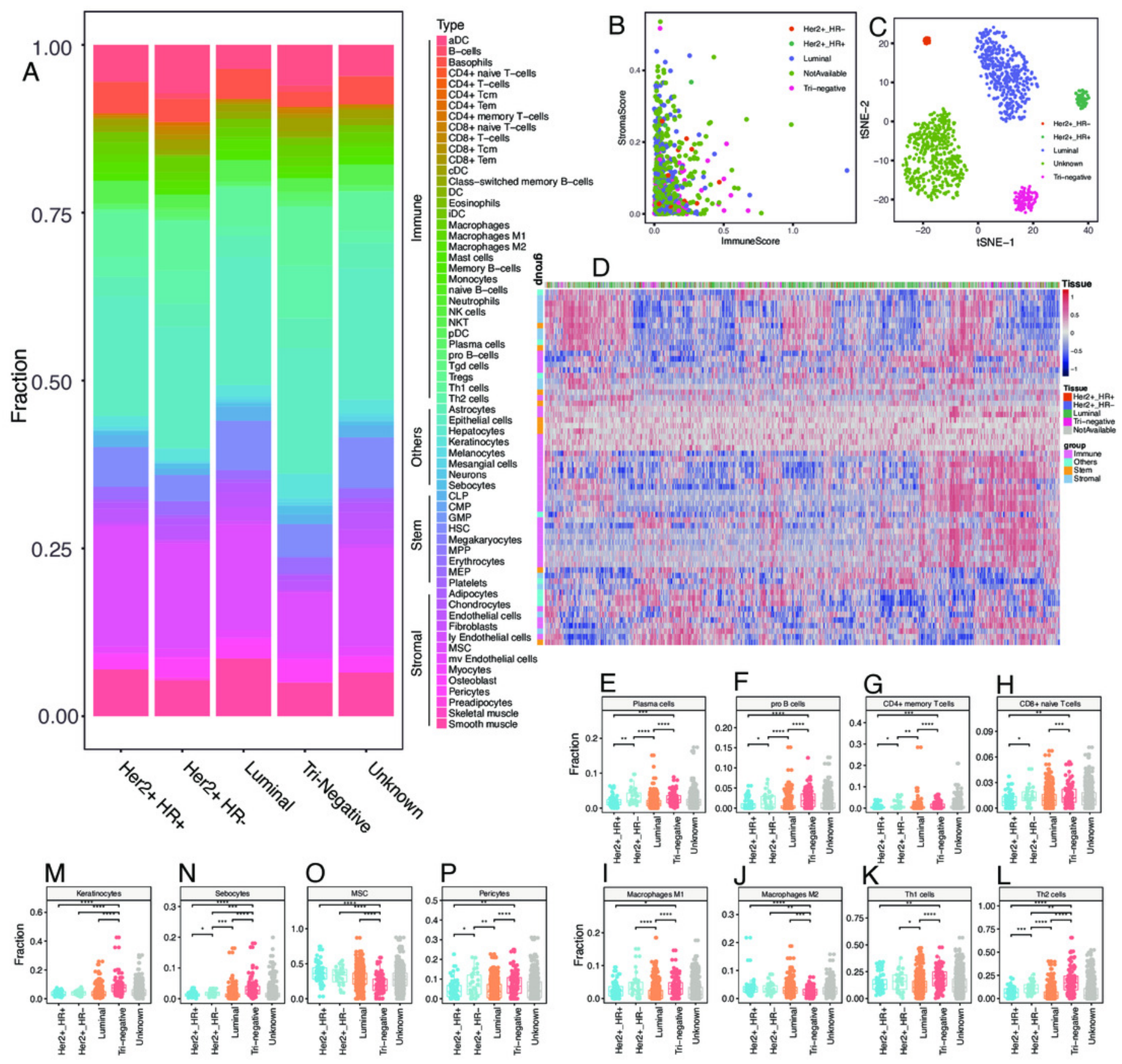


Figure 7

Survival associated tumor-infiltrating cells in five subtypes of breast cancer.

A. to E. Forest plots of hazard ratios of survival associated cell types in five subtypes of breast cancer.

A
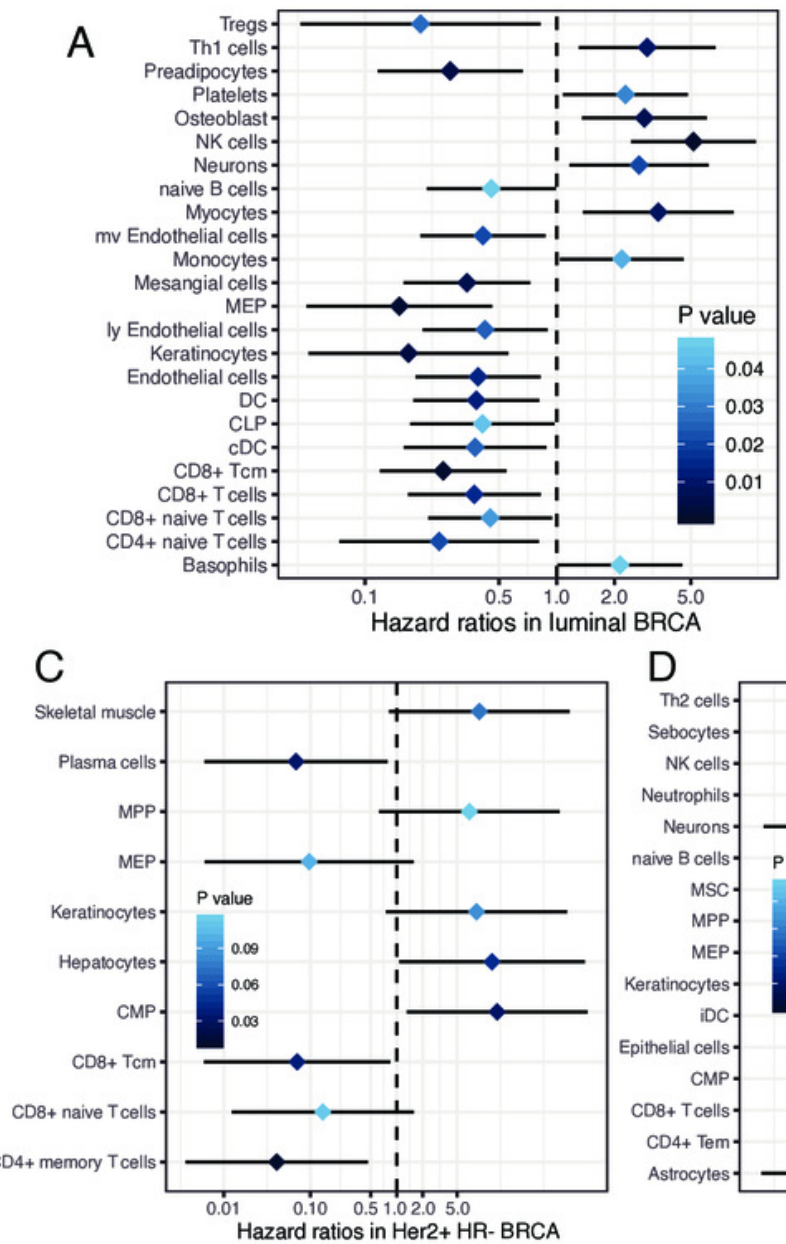

D
B
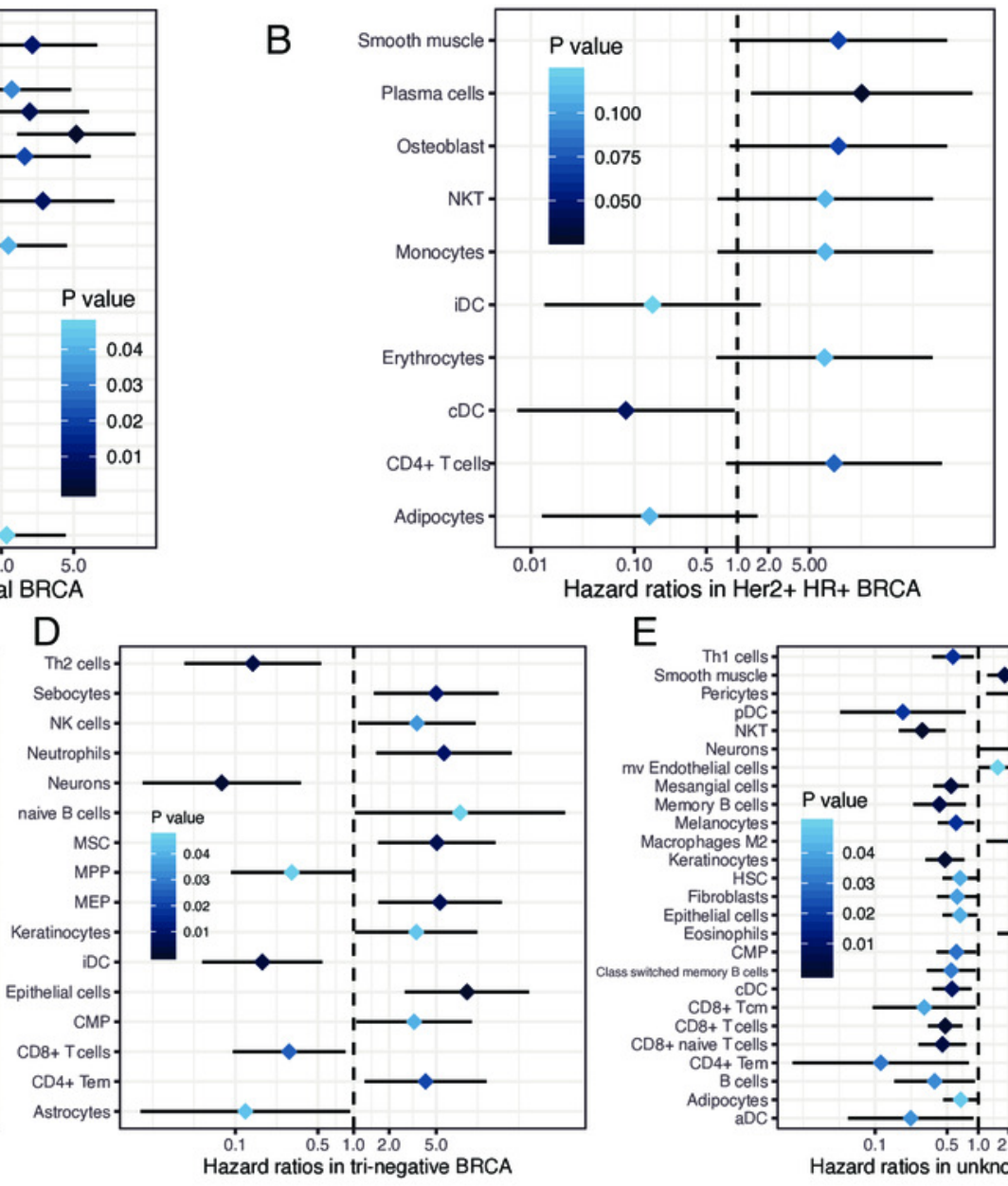

$\mathrm{E}$

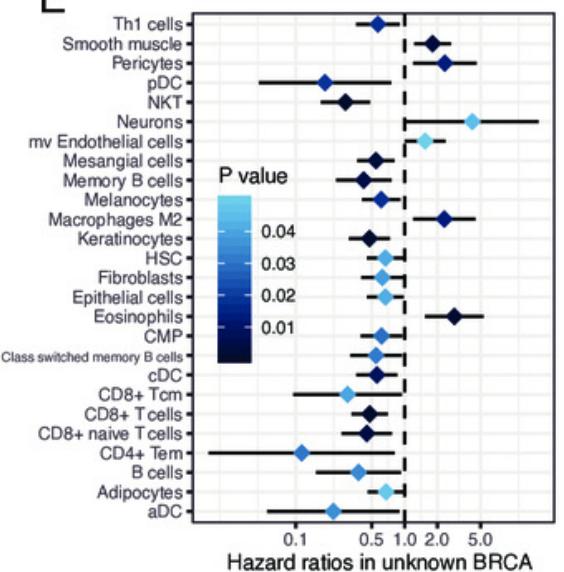




\section{Table 1 (on next page)}

Clinical characteristics of the 1,092 breast cancer patients from TCGA.

Clinical characteristics of the 1,092 breast cancer patients from TCGA. 
Table 1. Clinical characteristics of the 1,092 breast cancer patients from TCGA.

\begin{tabular}{ll}
\hline Characteristic & $\begin{array}{l}\text { TCGA BRCA } \\
\text { (N=1,092) }\end{array}$ \\
\hline $\begin{array}{l}\text { Age median (range) } \\
\text { Sex }\end{array}$ & $59(26-90)$ \\
Female & $1,080(98.9 \%)$ \\
Male & $12(1.1 \%)$ \\
Tumor stage & \\
T1 & $279(25.5 \%)$ \\
T2 & $635(58.2 \%)$ \\
T3 & $138(12.6 \%)$ \\
T4 & $40(3.7 \%)$ \\
Lymph node stage & \\
N (-) & $333(30.5 \%)$ \\
N (+) & $759(69.5 \%)$ \\
Metastasis stage & \\
M (-) & $903(82.7 \%)$ \\
M (+) & $189(17.3 \%)$ \\
TNM stage & \\
TNM I & $181(16.5 \%)$ \\
TNM II & $637(58.3 \%)$ \\
TNM II & $254(23.3 \%)$ \\
TNM IV & $20(18.3 \%)$ \\
Subtypes & \\
Luminal & $426(39.0 \%)$ \\
Her2+_HR+ & $59(5.4 \%)$ \\
Her2+_HR- & \\
Tri-negative & \\
Unknown & \\
Status & \\
Living & \\
Decreased & $(2.7 \%)$ \\
\hline
\end{tabular}




\section{Table 2 (on next page)}

Abbreviations and statistical summary of enriched fractions of the 64 cell types.

Abbreviations and statistical summary of enriched fractions of the 64 cell types. 
Table 2. Abbreviations and statistical summary of enriched fractions of the 64 cell types.

\begin{tabular}{|c|c|c|c|c|c|c|c|}
\hline Full name & Abbreviations & Group & $\begin{array}{l}\text { Tumor } \\
\mathrm{N}=1,092 \\
\text { (Mean } \pm \text { SD) }\end{array}$ & $\begin{array}{l}\text { Normal } \\
\mathrm{N}=112 \\
\text { (Mean } \pm \mathrm{SD} \text { ) }\end{array}$ & $\begin{array}{l}\text { Paired Tumor } \\
\mathrm{N}=112 \\
\text { (Mean } \pm \mathrm{SD} \text { ) }\end{array}$ & $\begin{array}{l}\mathrm{P} \\
\text { value }\end{array}$ & $\begin{array}{l}\text { P value } \\
\text { (paired) }\end{array}$ \\
\hline $\begin{array}{l}\text { Activated } \\
\text { dendritic cells }\end{array}$ & $\mathrm{aDC}$ & Immune & $0.116 \pm 0.110$ & $0.016 \pm 0.045$ & $0.103 \pm 0.104$ & $<0.001$ & $<0.001$ \\
\hline B-cells & l & Immune & $0.031 \pm 0.085$ & $0.004 \pm 0.039$ & $0.021 \pm 0.052$ & $<0.001$ & $<0.001$ \\
\hline Basophils & l & Immune & $0.078 \pm 0.056$ & $0.058 \pm 0.040$ & $0.071 \pm 0.054$ & $<0.001$ & 0.077 \\
\hline $\begin{array}{l}\text { CD4+ naive } \mathrm{T}- \\
\text { cells }\end{array}$ & l & Immune & $0.010 \pm 0.029$ & $0.003 \pm 0.015$ & $0.008 \pm 0.020$ & 0.009 & 0.004 \\
\hline CD4+ T-cells & I & Immune & $0.003 \pm 0.010$ & $0.000 \pm 0.003$ & $0.001 \pm 0.004$ & 0.101 & 0.036 \\
\hline $\begin{array}{l}\text { Central memory } \\
\text { CD4+ T Cell }\end{array}$ & $\mathrm{CD} 4+\mathrm{Tcm}$ & Immune & $0.009 \pm 0.015$ & $0.016 \pm 0.019$ & $0.003 \pm 0.007$ & 0.006 & $<0.001$ \\
\hline $\begin{array}{l}\text { Effector memory } \\
\text { CD4+ T cell }\end{array}$ & $\mathrm{CD} 4+\mathrm{Tem}$ & Immune & $0.013 \pm 0.022$ & $0.000 \pm 0.002$ & $0.010 \pm 0.018$ & $<0.001$ & $<0.001$ \\
\hline $\begin{array}{l}\text { CD4+ memory T- } \\
\text { cells }\end{array}$ & & Immune & $0.007 \pm 0.017$ & $0.000 \pm 0.004$ & $0.007 \pm 0.012$ & $<0.001$ & $<0.001$ \\
\hline $\begin{array}{l}\text { CD8+ naive } T- \\
\text { cells }\end{array}$ & l & Immune & $0.012 \pm 0.011$ & $0.005 \pm 0.007$ & $0.011 \pm 0.010$ & $<0.001$ & $<0.001$ \\
\hline CD8+ T-cells & l & Immune & $0.018 \pm 0.039$ & $0.006 \pm 0.016$ & $0.016 \pm 0.032$ & $<0.001$ & 0.001 \\
\hline $\begin{array}{l}\text { Central memory } \\
\text { CD8+ T Cell }\end{array}$ & $\mathrm{CD} 8+\mathrm{Tcm}$ & Immune & $0.026 \pm 0.049$ & $0.005 \pm 0.015$ & $0.027 \pm 0.046$ & $<0.001$ & $<0.001$ \\
\hline $\begin{array}{l}\text { Effector memory } \\
\text { CD8+ T cell }\end{array}$ & CD8+ Tem & Immune & $0.001 \pm 0.007$ & $0.000 \pm 0.000$ & $0.000 \pm 0.002$ & 0.805 & 0.608 \\
\hline $\begin{array}{l}\text { Conventional } \\
\text { dendritic cells }\end{array}$ & $\mathrm{cDC}$ & Immune & $0.037 \pm 0.046$ & $0.072 \pm 0.057$ & $0.040 \pm 0.043$ & $<0.001$ & $<0.001$ \\
\hline $\begin{array}{l}\text { Class-switched } \\
\text { memory B-cells }\end{array}$ & l & Immune & $0.026 \pm 0.031$ & $0.002 \pm 0.014$ & $0.020 \pm 0.023$ & $<0.001$ & $<0.001$ \\
\hline Dendritic cells & $\mathrm{DC}$ & Immune & $0.005 \pm 0.011$ & $0.005 \pm 0.011$ & $0.004 \pm 0.008$ & 0.826 & 0.927 \\
\hline Eosinophils & I & Immune & $0.000 \pm 0.001$ & $0.000 \pm 0.000$ & $0.000 \pm 0.001$ & 0.737 & 0.763 \\
\hline $\begin{array}{l}\text { Immature } \\
\text { dendritic cells }\end{array}$ & iDC & Immune & $0.042 \pm 0.073$ & $0.167 \pm 0.171$ & $0.047 \pm 0.053$ & $<0.001$ & $<0.001$ \\
\hline Macrophages & I & Immune & $0.038 \pm 0.036$ & $0.008 \pm 0.023$ & $0.038 \pm 0.034$ & $<0.001$ & $<0.001$ \\
\hline $\begin{array}{l}\text { Inflammatory } \\
\text { (M1) }\end{array}$ & $\begin{array}{l}\text { Macrophages } \\
\text { M1 }\end{array}$ & Immune & $0.022 \pm 0.027$ & $0.003 \pm 0.010$ & $0.019 \pm 0.027$ & $<0.001$ & $<0.001$ \\
\hline macrophages & & & & & & & \\
\hline $\begin{array}{l}\text { Reparative (M2) } \\
\text { macrophages }\end{array}$ & $\begin{array}{l}\text { Macrophages } \\
\text { M2 }\end{array}$ & Immune & $0.031 \pm 0.021$ & $0.030 \pm 0.034$ & $0.031 \pm 0.017$ & 0.001 & 0.003 \\
\hline Mast cells & I & Immune & $0.024 \pm 0.012$ & $0.015 \pm 0.008$ & $0.025 \pm 0.010$ & $<0.001$ & $<0.001$ \\
\hline Memory B-cells & I & Immune & $0.006 \pm 0.028$ & $0.001 \pm 0.011$ & $0.003 \pm 0.014$ & $<0.001$ & 0.083 \\
\hline Monocytes & I & Immune & $0.004 \pm 0.012$ & $0.003 \pm 0.013$ & $0.004 \pm 0.011$ & 0.007 & 0.040 \\
\hline
\end{tabular}




\begin{tabular}{|c|c|c|c|c|c|c|c|}
\hline naive $B$-cells & 1 & Immune & $0.004 \pm 0.016$ & $0.001 \pm 0.009$ & $0.003 \pm 0.009$ & $<0.001$ & 0.004 \\
\hline Neutrophils & 1 & Immune & $0.000 \pm 0.001$ & $0.003 \pm 0.005$ & $0.000 \pm 0.000$ & $<0.001$ & $<0.001$ \\
\hline Nature killer cells & NK cells & Immune & $0.000 \pm 0.002$ & $0.000 \pm 0.000$ & $0.000 \pm 0.001$ & 0.342 & 0.759 \\
\hline $\begin{array}{l}\text { Natural killer T } \\
\text { cells }\end{array}$ & NKT & Immune & $0.061 \pm 0.039$ & $0.028 \pm 0.036$ & $0.043 \pm 0.028$ & $<0.001$ & $<0.001$ \\
\hline $\begin{array}{l}\text { Plasmacytoid } \\
\text { dendritic cells }\end{array}$ & $\mathrm{pDC}$ & Immune & $0.008 \pm 0.019$ & $0.000 \pm 0.000$ & $0.007 \pm 0.017$ & $<0.001$ & 0.004 \\
\hline Plasma cells & I & Immune & $0.019 \pm 0.018$ & $0.001 \pm 0.003$ & $0.015 \pm 0.012$ & $<0.001$ & $<0.001$ \\
\hline pro B-cells & I & Immune & $0.009 \pm 0.017$ & $0.000 \pm 0.000$ & $0.006 \pm 0.013$ & $<0.001$ & $<0.001$ \\
\hline $\begin{array}{l}\text { Gamma delta } \mathrm{T} \\
\text { cells }\end{array}$ & Tgd cells & Immune & $0.003 \pm 0.009$ & $0.000 \pm 0.000$ & $0.004 \pm 0.011$ & $<0.001$ & 0.003 \\
\hline $\begin{array}{l}\text { Regulatory } \quad T \\
\text { cells }\end{array}$ & Tregs & Immune & $0.012 \pm 0.016$ & $0.004 \pm 0.009$ & $0.013 \pm 0.016$ & $<0.001$ & $<0.001$ \\
\hline $\begin{array}{l}\text { Type } 1 \mathrm{~T} \text { helper } \\
\text { (Th1) cells }\end{array}$ & Th1 cells & Immune & $0.133 \pm 0.092$ & $0.014 \pm 0.026$ & $0.101 \pm 0.067$ & $<0.001$ & $<0.001$ \\
\hline $\begin{array}{l}\text { Type } 2 \text { T helper } \\
\text { (Th2) cells }\end{array}$ & Th2 cells & Immune & $0.075 \pm 0.096$ & $0.002 \pm 0.007$ & $0.082 \pm 0.091$ & $<0.001$ & $<0.001$ \\
\hline Astrocytes & I & Others & $0.076 \pm 0.069$ & $0.110 \pm 0.065$ & $0.081 \pm 0.064$ & $<0.001$ & $<0.001$ \\
\hline Epithelial cells & I & Others & $0.365 \pm 0.092$ & $0.277 \pm 0.146$ & $0.354 \pm 0.089$ & $<0.001$ & $<0.001$ \\
\hline Hepatocytes & I & Others & $0.001 \pm 0.002$ & $0.005 \pm 0.003$ & $0.002 \pm 0.002$ & $<0.001$ & $<0.001$ \\
\hline Keratinocytes & l & Others & $0.047 \pm 0.038$ & $0.065 \pm 0.037$ & $0.046 \pm 0.038$ & $<0.001$ & $<0.001$ \\
\hline Melanocytes & l & Others & $0.010 \pm 0.008$ & $0.008 \pm 0.008$ & $0.010 \pm 0.009$ & 0.011 & 0.162 \\
\hline Mesangial cells & l & Others & $0.014 \pm 0.015$ & $0.034 \pm 0.013$ & $0.015 \pm 0.015$ & $<0.001$ & $<0.001$ \\
\hline Neurons & l & Others & $0.004 \pm 0.008$ & $0.004 \pm 0.002$ & $0.004 \pm 0.006$ & $<0.001$ & $<0.001$ \\
\hline Sebocytes & l & Others & $0.016 \pm 0.019$ & $0.009 \pm 0.009$ & $0.017 \pm 0.024$ & $<0.001$ & $<0.001$ \\
\hline $\begin{array}{l}\text { Common } \\
\text { lymphoid } \\
\text { progenitor }\end{array}$ & CLP & Stem & $0.039 \pm 0.026$ & $0.013 \pm 0.015$ & $0.041 \pm 0.026$ & $<0.001$ & $<0.001$ \\
\hline $\begin{array}{l}\text { Common } \\
\text { myeloid } \\
\text { progenitor }\end{array}$ & $\mathrm{CMP}$ & Stem & $0.001 \pm 0.003$ & $0.003 \pm 0.004$ & $0.001 \pm 0.003$ & $<0.001$ & 0.008 \\
\hline $\begin{array}{l}\text { Granulocyte- } \\
\text { macrophage } \\
\text { progenitor }\end{array}$ & GMP & Stem & $0.002 \pm 0.006$ & $0.002 \pm 0.006$ & $0.002 \pm 0.008$ & 0.001 & 0.025 \\
\hline $\begin{array}{l}\text { Hematopoietic } \\
\text { stem cells }\end{array}$ & $\mathrm{HSC}$ & Stem & $0.150 \pm 0.110$ & $0.492 \pm 0.191$ & $0.174 \pm 0.125$ & $<0.001$ & $<0.001$ \\
\hline Megakaryocytes & I & Stem & $0.004 \pm 0.004$ & $0.021 \pm 0.009$ & $0.005 \pm 0.005$ & $<0.001$ & $<0.001$ \\
\hline $\begin{array}{l}\text { Multipotent } \\
\text { progenitors }\end{array}$ & MPP & Stem & $0.00 \pm 0.001$ & $0.000 \pm 0.000$ & $0.000 \pm 0.000$ & $<0.001$ & 0.027 \\
\hline Erythrocytes & I & Stem & $0.000 \pm 0.000$ & $0.000 \pm 0.000$ & $0.000 \pm 0.000$ & 0.471 & 0.306 \\
\hline Megakaryocyte- & MEP & Stem & $0.035 \pm 0.030$ & $0.011 \pm 0.017$ & $0.027 \pm 0.022$ & $<0.001$ & $<0.001$ \\
\hline
\end{tabular}




\begin{tabular}{|c|c|c|c|c|c|c|c|}
\hline $\begin{array}{l}\text { erythroid } \\
\text { progenitor }\end{array}$ & & & & & & & \\
\hline Platelets & l & Stem & $0.000 \pm 0.002$ & $0.000 \pm 0.001$ & $0.000 \pm 0.001$ & 0.062 & 0.334 \\
\hline Adipocytes & l & Stromal & $0.050 \pm 0.088$ & $0.382 \pm 0.207$ & $0.063 \pm 0.102$ & $<0.001$ & $<0.001$ \\
\hline Chondrocytes & I & Stromal & $0.035 \pm 0.037$ & $0.053 \pm 0.022$ & $0.040 \pm 0.038$ & $<0.001$ & $<0.001$ \\
\hline Endothelial cells & l & Stromal & $0.058 \pm 0.056$ & $0.209 \pm 0.104$ & $0.066 \pm 0.059$ & $<0.001$ & $<0.001$ \\
\hline Fibroblasts & I & Stromal & $0.058 \pm 0.068$ & $0.172 \pm 0.078$ & $0.063 \pm 0.074$ & $<0.001$ & $<0.001$ \\
\hline $\begin{array}{l}\text { Lymphatic } \\
\text { endothelial cells }\end{array}$ & $\begin{array}{l}\text { ly Endothelial } \\
\text { cells }\end{array}$ & Stromal & $0.020 \pm 0.027$ & $0.110 \pm 0.071$ & $0.021 \pm 0.025$ & $<0.001$ & $<0.001$ \\
\hline $\begin{array}{l}\text { Mesenchymal } \\
\text { stem cells }\end{array}$ & MSC & Stromal & $0.281 \pm 0.144$ & $0.019 \pm 0.054$ & $0.252 \pm 0.139$ & $<0.001$ & $<0.001$ \\
\hline $\begin{array}{l}\text { Microvascular } \\
\text { endothelial cells }\end{array}$ & $\begin{array}{l}\text { mv Endothelial } \\
\text { cells }\end{array}$ & Stromal & $0.032 \pm 0.032$ & $0.104 \pm 0.062$ & $0.029 \pm 0.028$ & $<0.001$ & $<0.001$ \\
\hline Myocytes & I & Stromal & $0.004 \pm 0.010$ & $0.009 \pm 0.042$ & $0.005 \pm 0.008$ & 0.012 & 0.387 \\
\hline Osteoblast & I & Stromal & $0.025 \pm 0.031$ & $0.005 \pm 0.013$ & $0.018 \pm 0.024$ & $<0.001$ & $<0.001$ \\
\hline Pericytes & I & Stromal & $0.053 \pm 0.052$ & $0.027 \pm 0.035$ & $0.057 \pm 0.055$ & $<0.001$ & $<0.001$ \\
\hline Preadipocytes & I & Stromal & $0.024 \pm 0.040$ & $0.179 \pm 0.090$ & $0.032 \pm 0.045$ & $<0.001$ & $<0.001$ \\
\hline Skeletal muscle & I & Stromal & $0.001 \pm 0.011$ & $0.010 \pm 0.101$ & $0.001 \pm 0.003$ & 0.442 & 0.365 \\
\hline Smooth muscle & I & Stromal & $0.133 \pm 0.091$ & $0.125 \pm 0.067$ & $0.175 \pm 0.088$ & 0.345 & $<0.001$ \\
\hline ImmuneScore & I & I & $0.082 \pm 0.103$ & $0.029 \pm 0.049$ & $0.074 \pm 0.079$ & $<0.001$ & $<0.001$ \\
\hline StromaScore & l & 1 & $0.083 \pm 0.088$ & $0.382 \pm 0.174$ & $0.096 \pm 0.097$ & $<0.001$ & $<0.001$ \\
\hline
\end{tabular}

2 